\title{
Production of Monoclonal Antibodies Against Canine Leukocytes
}

\author{
PAULO HENRIQUE PALIS AGUIAR, ${ }^{1,2}$ ROBERTO ROBSON BORGES DOS SANTOS, ${ }^{2}$ \\ CARLA ANDRADE LIMA, ${ }^{3}$ HILTON RIOS DE SOUSA GOMES, ${ }^{3}$ DANIELA FARIAS LARANGEIRA, ${ }^{2}$ \\ PATRÍCIA MEIRA SANTOS, ${ }^{2}$ STELLA MARIA BARROUIN-MELO,${ }^{1,2}$ \\ WASHINGTON LUIS CONRADO DOS-SANTOS, ${ }^{1,3}$ and LAIN PONTES-DE-CARVALHO ${ }^{1,3}$
}

\begin{abstract}
A panel of anti-canine leukocyte monoclonal antibodies (MAbs) was produced by immunizing BALB/c mice with canine peripheral blood mononuclear cells (PBMC), either resting or stimulated with concanavalin A (ConA). Three out of 28 clones-IH1, AB6, and HG6-screened by ELISA and producing antibody with the highest specificity for canine cell immunostaining, were subjected to three subsequent subcloning steps by limiting dilution, and selected for further characterization. These MAbs belonged to IgG1 (HG6 and IH1) and IgG2a (AB6) isotypes. The distribution of cell populations expressing the antigen recognized by the antibodies was identified by indirect immunoflorescence on canine PBMC and on tissue sections of lymph node, spleen, liver and skin. The possible crossreactivity with human PBMC was also examined in immunocytochemistry. One of the antibodies specifically recognized macrophages. The MAbs presented here can be foreseen as possible valuable diagnostic and research tools to study immune functions in dogs.
\end{abstract}

\section{INTRODUCTION}

$\mathbf{T}$ HERE IS A GREAT DEMAND for reagents to identify and characterize the canine immune response. In many human diseases that also occur in the dog, such as allergic asthma, ${ }^{(1)}$ penfigus, systemic lupus eritematosus, congenital or acquired immunodeficiency ${ }^{(2)}$ and in zoonosis such as leishmaniasis, ${ }^{(3)}$ immunological mechanisms play an important or central role in the genesis of the lesions and the progression of disease. Moreover, the accurate diagnosis of lymphoproliferative diseases such as lymphomas and leukemias, ${ }^{(4,5)}$ common in dogs, through the characterization of cell types and differentiation stages, is fundamental for treatment and definitions about the prognosis of the disease.

Dogs are also used in transplantation studies which require immunosuppressive intervention and as models for investigation of human diseases. ${ }^{(2)}$ Nevertheless, little is known about the dog immune system, and canine leukocyte markers are so far only poorly characterized. For example, high expression of
CD4 has been demonstrated in canine neutrophils, a condition that has not been observed in other species. ${ }^{(6)}$ There is, however, only a limited panel of available canine cell markers and this lack of reagents has impaired the development of studies on canine leukocyte pathology. ${ }^{(6-11)}$

In the present study, the production of 28 new monoclonal antibodies (MAbs) directed against canine leukocytes is reported. Three of these antibodies were selected for characterization, in order to build a panel of monoclonal antibodies against canine leukocytes with possible use for research and diagnosis of canine diseases.

\section{MATERIALS AND METHODS}

\section{Animals and tissues}

Two normal outbred dogs, with estimated ages of 24-36 months, with $15 \mathrm{~kg}$ of weight, were used throughout the study.

\footnotetext{
${ }^{1}$ Laboratory of Molecular and Cellular Immunology, Gonçalo Moniz Research Center, Oswaldo Cruz Foundation, Bahia, Brazil

${ }^{2}$ Department of Pathology and Clinics, Veterinary School, Federal University of Bahia, Bahia, Brazil.

${ }^{3}$ Bahiana School of Medicine, Medicine and Public Health, Foundation for Development of Science, Bahia, Brazil.
} 
The dogs were kept separately, under standard care and feeding conditions, in the kennel of Gonçalo Moniz Research Center, Oswaldo Cruz Foundation and used as blood donors. Normal dog tissues were from the Department of Pathology and Clinics, Veterinary School, Federal University of Bahia, and derived from necropsy material. Ten 6-month-old female Balb/c mice, maintained under standard conditions, from the breeding stock of the Gonçalo Moniz Research Center, were used for immunization with dog antigens. All the experiments were conducted according to the Oswaldo Cruz Foundation Guidelines for animal experimentation.

\section{Canine and human peripheral blood mononuclear cells (PBMC)}

Blood was collected by venipuncture of the cephalic vein into tubes containing enough heparin to produce a final concentration of $10 \mathrm{IU} \mathrm{mL}{ }^{-1}$. The peripheral blood mononuclear cells (PBMC) were isolated by centrifugation of diluted blood layered on Histopaque 1077 (Sigma Chemical Co., St. Louis, MO). Cells were washed twice in HBSS (Hank's balanced salt solution, Sigma Chemical Co.) before being used in the different steps.

\section{Antigen preparation}

Mitogen stimulated PBMC were obtained by incubating these cells in the concentration of $5 \times 10^{6} / \mathrm{mL}$, with $5 \mu \mathrm{g}$ of concanavalin A (ConA, Sigma Chemical Co.) in RPMI 1640 (Sigma Chemical Co.) supplemented with $100 \mathrm{IU} \mathrm{mL}^{-1}$ of penicillin, $100 \mu \mathrm{g} \mathrm{mL}^{-1}$ of streptomycin, $2 \mathrm{mM}$ L-glutamine and $20 \%$ of heat inactivated fetal calf serum (GIBCO, MD, USA), for $48 \mathrm{~h}$ in a $100 \%$ humidified atmosphere containing $5 \% \mathrm{CO}_{2}$ at $37^{\circ} \mathrm{C}$. Stimulated and non-stimulated canine PBMC were adjusted for $10^{7}$ cells $/ \mathrm{mL}$ and sonicated before emulsification with Freund's adjuvant.

\section{Immunization}

Groups of five BALB/c mice were immunized with ConAstimulated or non-stimulated canine PBMC, sonicated and emulsified with an equal volume of complete Freund's adjuvant (Sigma Chemical Co.). The animals were injected with an amount of antigen equivalent to $10^{7}$ cells per dose, one injection via intraperitoneal and two subcutaneous injections. Two identical boosters were given two and four weeks after the first immunization, using the same dose regimen, emulsified in incomplete Freund's adjuvant (Sigma Chemical Co.). Two weeks after the second booster, the mice were tested for the presence of circulating antibody against canine PBMC, by indirect ELISA. The animal with the highest antibody titer was injected intravenously with $10^{7}$ canine PBMC, lysed by sonication, in $200 \mu \mathrm{L}$ of $0.15 \mathrm{M}$ PBS, pH 7.2.

\section{Fusion}

Three days after the final booster, the animal was sacrificed and a single-cell splenocyte suspension was prepared and fused with the $\mathrm{SPO}_{2}$ myeloma cells, following standard procedures. ${ }^{(12)}$ After fusion, cells were distributed in ten 96-well tissue culture plates with RPMI supplemented with $100 \mathrm{IU} \mathrm{mL} \mathrm{mL}^{-1}$ of penicillin, $100 \mu \mathrm{g} \mathrm{mL}^{-1}$ of streptomycin, $2 \mathrm{mM} \mathrm{L}$-glutamine and $10 \%$ of heat inactivated fetal calf serum, supplemented with HAT (100mM hypoxantine, $0.4 \mu \mathrm{M}$ aminopterine and $16 \mu \mathrm{M}$ thymidine). After 14-21 days, hybrid cells showing antibody activity against canine leukocyte screened by ELISA, were cultured further using a layer of feeder cells from a nonimmunized BALB/c mouse to assist in the early stages of growth. Antibody-producingcells were subjected to three subsequent rounds of subcloning steps, by limiting dilution, for obtaining stable hybridomas. Culture supernatants were used in subsequent experiments.

\section{Cellular indirect enzyme-linked immunosorbent assay (ELISA)}

Canine PBMC were adjusted to the concentration of $5 \times$ $10^{5} / \mathrm{mL}$ in RPMI medium and $100 \mu \mathrm{L}$ of the cell suspension delivered into wells of a 96-well microplate (Nunc, Naperville, IL). The plate was centrifuged for $5 \mathrm{~min}$ at $700 \mathrm{~g}$, at $4^{\circ} \mathrm{C}$. After carefully discarding the supernatants with a multichannel pipette, the cells were air-dried at $37^{\circ} \mathrm{C}$ for at least $1 \mathrm{~h}$ and fixed for 5 min with $200 \mu \mathrm{L}$ of $100 \%$ ethanol. The plate was washed with PBS and the endogenousperoxidase was blocked with PBS containing $1 \% \mathrm{H}_{2} \mathrm{O}_{2}$ for $1 \mathrm{~h}$ at room temperature (RT). Remaining binding sites were blocked with $150 \mu \mathrm{L}$ of PBS containing 5\% skimmed milk powder (w/v), for $1 \mathrm{~h}$ at RT. MAb supernatants were tested at 1:2 dilution in PBS containing $0.05 \%$ Tween-20 (v/v), 5\% skimmed milk powder (w/v) and $10 \mu \mathrm{g} / \mathrm{mL}$ of rat IgG. After $1 \mathrm{~h}$ incubation at RT, the supernatants were removed, the plate was washed with PBS containing 0,05\% Tween-20 (PBS-Tween), and a peroxidaseconjugated polyclonal sheep anti-mouse IgG (Sigma Chemical Co.), diluted 1:1000, was added. After $1 \mathrm{~h}$ of incubation at RT the unbound conjugate was removed through washings with PBS-Tween. The reaction was revealed with $5 \mathrm{mg} / \mathrm{mL}$ of ortophenylenediamine (OPD, Sigma Chemical Co.) in citratephosphate buffer and stopped with $20 \mu \mathrm{L}$ of $4 \mathrm{~N} \mathrm{H}_{2} \mathrm{SO}_{4}$. Optical densities were read at $490 \mathrm{~nm} .^{(13)}$

\section{Isotyping of the monoclonal antibodies}

The isotypes of MAbs were determinated using a mouse monoclonal antibody isotyping kit (monoclonal antibody-based mouse Ig isotyping kit, B\&D PharMingen, Los Angeles, CA). The assay was performed following a protocol recommended by the manufacturer.

\section{Western blotting}

PBMC $\left(10^{7}\right.$ cells $)$ were lysed in SDS-PAGE sample buffer, pH 6.8 (Tris-HCl 62.5 mM, 2\% (w/v) SDS and 10\% (v/v) glycerol), under reducing (with 2-mercaptoethanol) and non-reducing (without 2-mercaptoethanol) conditions. The samples were loaded onto $0.7 \mathrm{~mm} 10 \%$ SDS (w/v) polyacrilamide slab gels, and electrophoresis performed as described elsewhere. ${ }^{(11)}$ Proteins were then elctrophoretically transferred to nitrocellulose membrane and subjected to Western blotting against the hybridoma supernatants diluted 1:2 with PBS-Tween containing $5 \%$ skimmed milk powder (w/v; PBS-T20-milk) as described previously, using peroxidase-conjugated sheep anti-mouse immunoglobulin polyclonal antibodies (Sigma Chemical Co.) and a mixture of 3,3'-diaminobenzidine (Sigma Chemical Co.) and 
$\mathrm{H}_{2} \mathrm{O}_{2}$ in PBS. A normal mouse serum dilution containing approximately $25 \mu \mathrm{g}$ of immunoglobulin per ml of PBS-T20-milk was used as negative control.

\section{Immunopreciptation}

Canine spleen cells were suspended in PBS (pH 7.2) and subjected 12 times to sonification with bursts of $20 \mathrm{sec}$ (Sonigier 450/Brandson) and treated with $100 \mathrm{mM} \mathrm{NaCl}$ and $1 \mathrm{mM} \mathrm{PMSF}$ for $1 \mathrm{~h}$ at $4{ }^{\circ} \mathrm{C}$. Insoluble fractions were removed by microcentrifugation at $15000 \mathrm{rpm}$ for $30 \mathrm{~min}$. Before immunopreciptation, MAbs were coupled to protein A-sepharose beads (Pharmacia, Uppsala, Sweden). The preclearation of all the spleen cell extracts was made with $1 \mathrm{~mL}$ of proteins for $1 \mathrm{~h}$ with 100 $\mu \mathrm{L}$ of protein A-sepharose beads. Then the mixture was incubated with $100 \mu$ l of each MAb-coated sepharose beads for $1 \mathrm{~h}$ at $4^{\circ} \mathrm{C}$ with continuous rotation. The beads were washed with PBS-T, resuspended with sample buffer and subjected to SDS-PAGE. The bands corresponding to the molecules recognized by the MAbs were visualized by western blotting.

\section{Indirect immunofluorescence}

Immunofluorescence reactions were preceded on permeabilized or non-permeabilized canine and human PBMC with Tween-20. Also, cryostat sections (6-8 $\mu \mathrm{m}$ in thickness) of canine normal lymph node, spleen, liver, skin, and kidney were carried out and tested by indirect immunofluorescence. PBMC or tissue sections were air-dried and fixed in alcohol for $5 \mathrm{~min}$ utes at RT. After three washes in PBS, the tissue sections and $\mathrm{PBMC}$ were incubated for $30 \mathrm{~min}$ at $37^{\circ} \mathrm{C}$ with hybridoma supernatants diluted 1:2 in PBS or PBS-Tween $(0,05 \%)$ with skimmed milk. The detergent was used for membrane permeabilization to guarantee the access of the MAbs to cytoplasm epitopes. Irrelevant antibody, diluent and normal mouse serum (diluted 1:500) were used as negative controls. The wells were washed three times in PBS and incubated for $30 \mathrm{~min}$ with secondary fluoresceine isothiocyanate (FITC)-conjugated sheep IgG anti-mouse immunoglobulins (Sigma Chemical Co.) diluted 1:200 in Blue Evans working solution. The slides were then washed three times with PBS for 10 minutes mounted with glycerol buffer and examined by UV microscopy.

\section{Production of isotype control immunoglobulins}

Normal mouse immunoglobulins with the same isotypes of the MAbs were used as controls for monoclonal antibody activity. A globulin-rich fraction was prepared from sera obtained from healthy female BALB/c mice by precipitation with $40 \%$ saturated ammonium sulphate. After dialysis against $\mathrm{PBS} \mathrm{pH}$ 8, mouse IgG1, IgG2a, and IgG2b immunoglobulins were purified from the globulin fraction by affinity chromatography on protein A-Sepharose 4B (Amersham Pharmacia Biotech, Uppsala, Sweden) with immunoglobulins isotype elution as a function of $\mathrm{pH} .^{(14)}$ Briefly, when the globulin fraction was applied on the column at $\mathrm{pH} 8.0, \operatorname{IgM}, \operatorname{IgA}$, and $\operatorname{IgE}$ were almost quantitatively recovered in the effluent, together with nonimmunoglobulin serum components and essentially all $\mathrm{IgG}$ was retained at the column. Using buffers of decreasing $\mathrm{pH}, \mathrm{IgG} 1$, IgG2a, and IgG2b were sequentially eluted at $\mathrm{pH} 6.0-7.0, \mathrm{pH}$ $4.5-5.0$ and $\mathrm{pH} 3.5-4.0$, respectively. The eluted immunoglobulins were tested for isotype and stored at $-20^{\circ} \mathrm{C}$.

\section{Macrophage differentiation in vitro}

Canine PBMC were adjusted to the concentration of $5 \times$ $10^{6} / \mathrm{mL}$ in RPMI medium supplemented with $20 \%$ of heat inactivated fetal calf serum and $500 \mu \mathrm{L}$ of the cell suspension were delivered into flat-bottomed six-well culture plates (Nunc, Naperville, IL), carefully washed after $24 \mathrm{~h}$ and incubated for 5-10 days in a humidified atmosphere at $37^{\circ} \mathrm{C}$ and $5 \% \mathrm{CO}_{2}$. Canine macrophages, differentiated from peripheral blood monocytes, adhered to the well bottoms and were used in indirect immunofluorescence tests using the MAbs and control immunoglobulins as described above.

\section{RESULTS}

Twenty-eight clones obtained from the fusions recognized canine leukocyte antigens in ELISA, yielding three stabilized hybridomas, with different specificities, named AB6, IH1 and HG6, which were selected for further characterization.

The isotyping of the three studied hybridomas revealed that the AB6 produced an IgG2a monoclonal antibody; and HG6 and $\mathrm{IH} 1$ produced monoclonal antibodies of the IgG1 subclass.

Data on the staining pattern of canine PBMC by immunocytochemistry and on the molecular weights of the antigens recognized by the MAbs in Western blotting analysis are summarized in Table 1. Under non-reducing conditions, the AB6 and HG6 MAbs detected single protein bands with molecular weights of 185 and $46 \mathrm{kDa}$, respectively. The IH1 MAb recognized a broad protein band spread out between 76 and 45 $\mathrm{kDa}$ (Fig. 1). Under reducing conditions, no antigenic band was detected by any of these antibodies. We further investigated whether the MAbs were useful for immunopreciptation of canine leukocyte molecules. Canine spleen cell extracts were in-

Table 1. Monoclonal Antibody Isotypes, Molecular Characterization, Immunological Cross-Reaction on the Human PBMC by Indirect Immunofluorescence and Staining Pattern of the Canine PBMC-Specific Monoclonal Antibodies

\begin{tabular}{lccccc}
\hline MAbs & Isotypes & $M W(k D a)$ & $\begin{array}{c}\text { Reaction } \\
\text { human-PBMC }\end{array}$ & Population & Staining pattern \\
\hline AB6 & IgG2a & 185 & Neg & LY, PMNN & Diffuse-membrane and cytoplasm \\
HG6 & IgG1 & 46 & Neg & LY & Diffuse-membrane and cytoplasm \\
IH1 & IgG1 & $73-45$ & Neg & LY, M $\phi$ & Focal一membrane and cytoplasm \\
\hline
\end{tabular}

neg, negative; Ly, lymphocytes; PMNN, polymorphonuclears; M $\phi$, macrophages. 


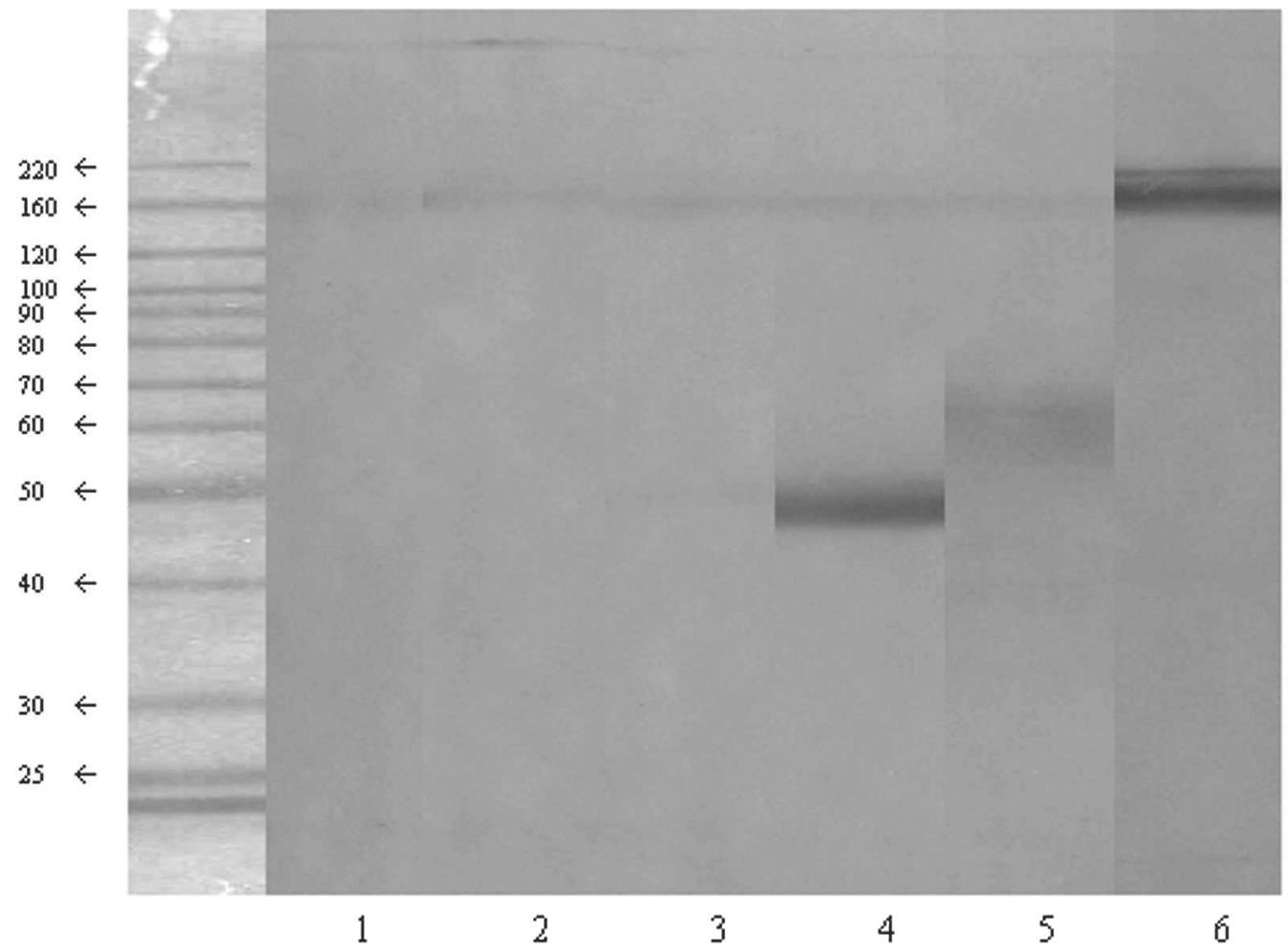

FIG. 1. Western blot of the cell lysates of canine PBMC in nitrocellulose membrane after transferring from non-denaturating SDS-PAGE showing reactivity of MAbs and controls: saline (1); normal mouse serum (2); anti-Leishmania MAb (3); HG6 MAb (4); IH1 MAb (5); and Ab6 MAb (6). On the left side is the molecular weight pattern stained in Comassie Blue to show the relative molecular weight of the recognized proteins by the MAbs.

cubated with protein A-sepharose beads coated with each MAb and the immunoprecipitates were visualized by western blot analyses using the MAbs AB6, HG6, and IH1.

The AB6, HG6, and IH1 MAbs stained cells with and without membrane permeabilization with Tween-20. The IH1 MAb stained a small population of PBMC cells with morphologic characteristics of monocytes, and also stained in vitro peripheral blood monocyte-derived macrophages (Fig. 2).
The three MAbs stained the cell membrane. The AB6 and HG6 MAbs showed a diffuse, homogeneous pattern of staining, while IH1 showed a multi-focal pattern on the cell surface (Table 1).

The three MAbs were tested in tissue preparations: IH1, AB6, and HG6. The IH1 proved its specificity for macrophages, showing a characteristic staining pattern in the spleen, lymph node and liver, in which the Kuppfer cells were stained. The other antibodies (AB6 and HG6) marked mononuclear cells in $\mathbf{a}$

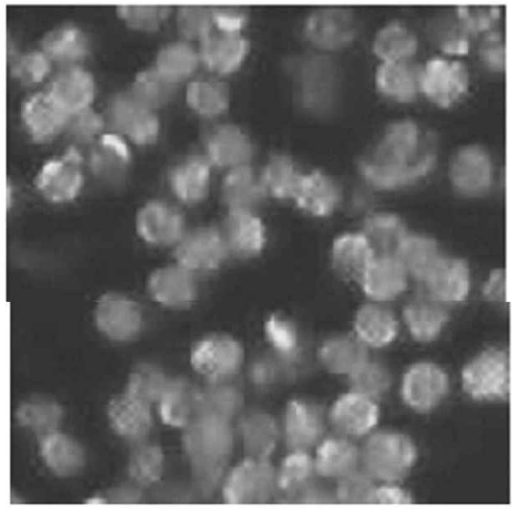

$\bar{b}$

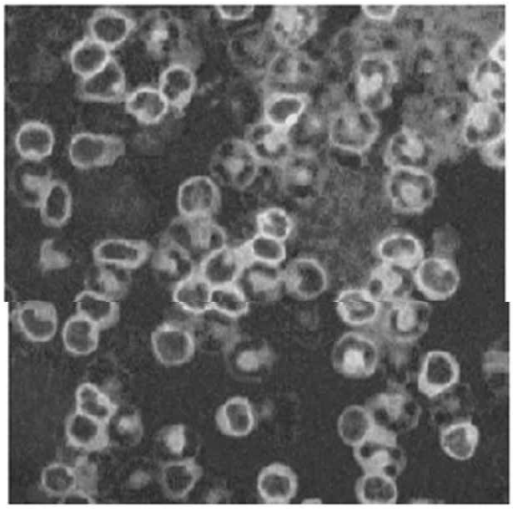

c

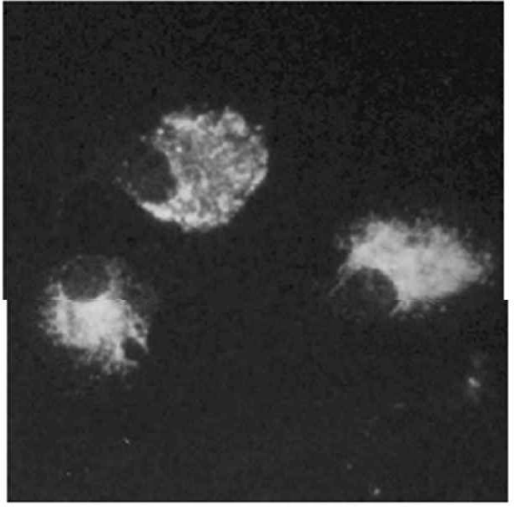

FIG. 2. Immunofluorescent staining of canine cells with MAbs: (a) Preparation of PBMC in suspension, stained with HG6 MAb showing a pan-leukocyte identification. (b) Preparation of PBMC by cito-centrifugation followed by acetone fixation and staining with AB6 MAb diluted in Blue Evans, identifying a lymphocyte subset. (c) Canine macrophages differentiated from a peripheral blood monocytes culture, stained by the IH1 MAb. $\times 400$. 
spleen and lymph node. HG6 stained only large mononuclear and not reticular cells, in the germinative center of the follicle. AB6 stained a large population of mononuclear cells, including interstitial cells. In liver, HG6 stained Kuppfer cells, while AB6 marked only round lymphocyte-like cells, on small inflammatory foci in parenchyma. On the skin, AB6 and HG6 stained cells in inflammatory infiltrate foci, while IH1 and HG6 stained spindle cells, some of them with irregular projections, present in the edge of the hair follicles (Fig. 3). None of these MAbs cross-reacted with human PBMC (Table 1).

\section{DISCUSSION}

In this report, we present three monoclonal antibodies raised against canine leukocytes, including one recognizing macrophages. Under non-reducing conditions, all the MAbs identified different sharp single protein bands, varying from 185 to $45 \mathrm{kDa}$, demonstrating their different specificities. The IH1 MAb recognized a broad protein band, spread out between 76 and $45 \mathrm{kDa}$, similar to a glycosylated protein pattern. None of them show any reaction under reducing conditions, indicating that they may recognize conformational epitopes. The analyses of their reactivity against PBMC demonstrated that all were capable of identifying membrane and/or cytoplasm proteins, and none reacted only with cytoplasm proteins. Hence, the MAbs can possibly be used to identify specific caCDs or to modulate canine immune responses. Moreover, these MAbs recognized a variable pattern of epitope distributions on the cells, which could be classified as diffuse, and could indicate different roles on recognizing molecules in cell function.

The IH1 MAb identified monocyte/macrophage cells on the different tissues studied. Only a very small number of reported MAbs exhibit an exclusive reactivity with monocytes/macrophages..$^{(15,16)}$ None of these, however, have the same specificity as the IH1 MAb, which reacted with monocytes on peripheral blood, mature macrophages in cell cultures and different macrophage subpopulations in tissues, such as spleen cortical and red pulp, liver Kupffer cells and Langerhan's type cells in the skin.

The staining pattern produced by the HG6 MAb suggest that it identifies phagocytic leukocytes, while the pattern produced by the AB6 indicates that it recognizes lymphocytes.

In order to evaluate the ability to recognize leukocyte antigens from other species, the selected MAbs were assayed by immunofluorescence using human PBMC as targets. None of them identified epitopes on human leukocytes. It was reported that reactions of MAbs developed against human leukocytes with epitopes on canine cells happened at a relatively high proportion, suggesting that the recognized antigens may be conserved among philogenetically distant animals. ${ }^{(17)}$ In fact, $10 \%$ of cross-reactions were found by Joachin et al. ${ }^{(18)}$ using monoclonal antibodies, between leukocytes from different species, such as dog and cattle. However, although in some cases, MAbs directed against antigens from one species recognize leukocytes of other species, the majority of MAbs do not cross-react. $(6,8,15,19)$

A more extensive determination of the properties of the MAbs described herein would require further studies. The identification of the recognized antigens through their amino acid a

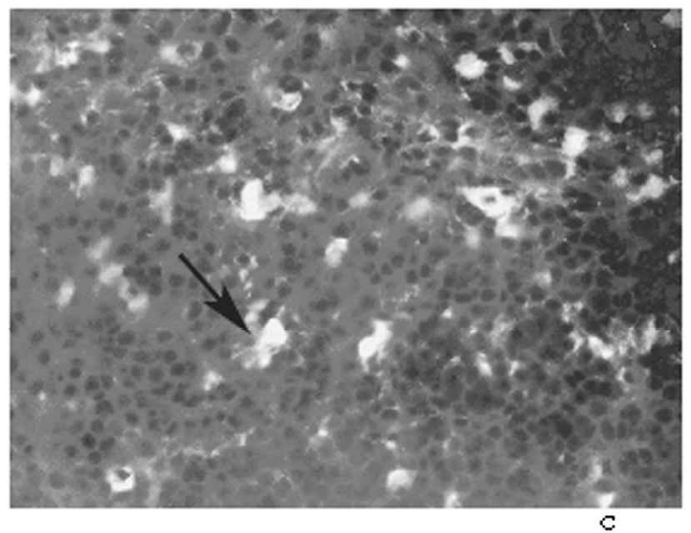

$c$

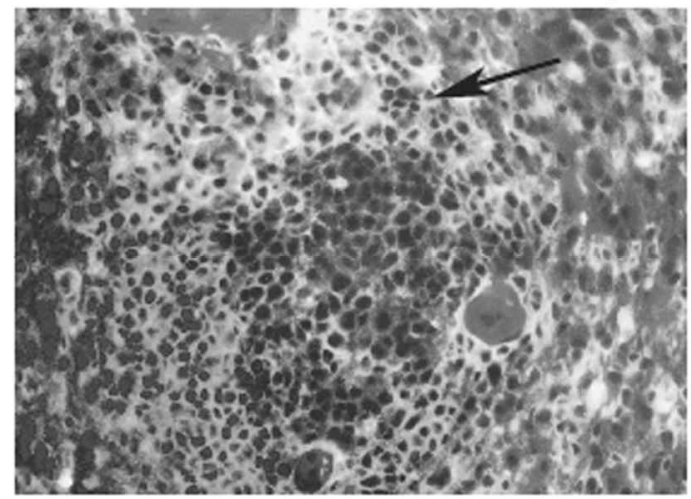

b

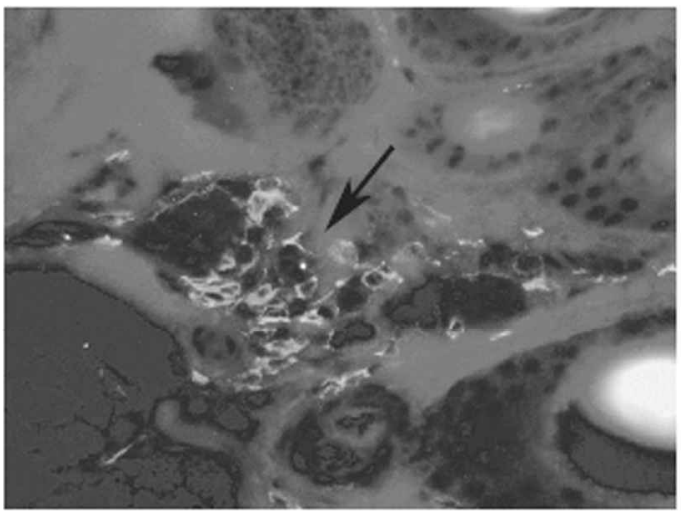

FIG. 3. Indirect immunofluorescence of frozen sections of canine tissues: (a) In a normal lymph node, the IH1 MAb stained large isolated cells in the cortical area. (b) Inflammatory infiltrate stained by the AB6 MAb in skin. (c) In the section of normal canine spleen, the HG6 MAb reacted with a majority of cells on the white pulp mantle zone. $\times 400$. 
sequencing would allow their use in immunotherapeutic studies of canine diseases in which the immune system plays a pathogenic role; in immunoassay-based diagnoses of lymphomas and leukemias, and in achieving a fuller understanding of the canine immune response in infection and autoimmunity.

\section{REFERENCES}

1. Eber E, Uhlig T, and McMenanin C: Lefluomide, a novel immunomodulating agent prevents the development of allergic sensitization in an animal model of allergic asthma. Clin Exp Allerg 1998;28:376-384.

2. Pedersen NC: A review of immunologic diseases of the dog. Vet Immunol Immunopathol 1999;69:254-342.

3. Pinelli E, Killick-Kendrick R, Wagenaar J, Bernadina W, del Real $\mathrm{G}$, and Ruitenberg J: Cellular and humoral responses in dogs experimentally and naturally infected with $L$. infantum. Infect Immun 1994;26:229-235.

4. Barker RN, Elson CJ: Red cell-reactive non-specific immunoglobulins and autoantibodies in the sera of normal and anaemic dogs. Vet Immunol Immunopathol 1993;39:339-354.

5. Breuer W, Colbatzky F, and Platz, S: Immunoglobulin-producing tumors in dogs and cats. J Comp Pathol 1993;109:203-216.

6. Willians D L: Studies of canine leucocyte antigens: a significant advance in canine immunology. The Veterinary Journal 1997;153: 31-39.

7. Cobbold S \& Metcalfe Su: Monoclonal antibodies that define canine homologues of human CD antigens: Summary of the First International Canine Leukocyte Antigen Workshop (CLAW). Tissue Antigens 1994;43:137-154.

8. Galkoswska H, Waldemar LO, Wojewodska U: Reactivity of antibodies directed against human antigens with surface markers on canine leukocytes. Veterinary Immunology Immunopathology 1996;53:329-334.

9. Borrebaeck CAK: Antibodies in diagnostics-from immunoassay to protein chips. Immunology Today 2000;21:379-382.

10. Herzenberg LA, DeRosa SC, Herzenberg LA: Monoclonal antibodies and the FACS: complementary tools for immunobiology and medicine. Immunology Today 2000;21:383-390.

11. Wunschmann A, Kremmer E, Baumgartner W: Phenotypical characterization of $\mathrm{T}$ and $\mathrm{B}$ cell areas in lymphoid tissues of dogs with spontaneous distemper. Veterinary Immunology Immunopathology 2000;73:83-98.
12. Harlow, E and Lane D: Antibodies: A laboratory Manual Cold Spring Harbor Laboratory Press, Cold Spring Harbor, NY, 1988.

13. Baumgarten H: A cell ELISA for the quantitation of leukocyte antigens. Journal of Immunological Methods 1986;94:91-98.

14. Ey PL, Prowse SJ and Jenkin CR: Isolation of pure IgG1, IgG2a and $\mathrm{IgG} 2 \mathrm{~b}$ immunoglobulins from mouse serum using protein ASepharose. Immunochemistry 1978;15,429-436.

15. Berndt A, Heller M, Methner U, Kosmehl H, Muller G: Monoclonal antibodies against porcine macrophages. Veterinary Immunology Immunopathology 2000;74:163-177.

16. Jacobsen CN, Aasted E, Broe MK and Petersen JL: Reactivities of 20 anti-human monoclonal antibodies with leucocytes from different animal species. Veterinary Immunology Immunopathology 1996;39:461-466.

17. Yamate J, Yoshida Y, Tsukamoto M, Ide M, Kuwamura F, Ohashi T, Miyamoto T, Kotani T, Sakuma S and Takeya M: Distribution of cells immunopositive for AM-3K, a novel monoclonal antibody recognizing human macrophages, in normal and diseased tissues of dogs, cats, horses, cattle, pigs and rabbits. Veterinary Pathology 2000;37:168-176.

18. Joachin SH, Beer A, Rabe HU, Leibold W: Reactivity of workshop antibodies with a non-ruminant species: crossreactivity with canine blood leukocytes. Veterinary Immunology Immunopathology 1996;52:427-433.

19. Brodersen R, Bijlsma F, Gori K, Jensen KT, Chen W, Dominguez J, Harveson K, Moore P, Saalmuller A, Sachs D, Slierendrecht WJ, Stockes C, Vainio O, Zuckermann F and Aaste B: Analysis of the immunological cross reactivities of 213 well characterized monoclonal antibodies with specificities against various leucocyte surface antigens of human and 11 animal species. Veterinary Immunology Immunopathology 1998;64:1-13.

Address reprint requests to: Paulo Henrique Palis Aguiar, D.V.M., M.S. Laboratory of Molecular and Cellular Immunology (LIMC) CPqGM-FIOCRUZ

Av Valdemar Falcão n.121 CEP:40295-001

Brotas, Salvador, Bahia, Brazil

E-mail:phpa@ufba.br

Received for publication December 7, 2003. Accepted for publication February 11, 2004. 